\title{
Poly- $\gamma$-Glutamic Acid (PGA)-Producing Bacillus Species Isolated from Kinema, Indian Fermented Soybean Food
}

\author{
Rajen Chettri, Meera O. Bhutia and Jyoti P. Tamang* \\ Department of Microbiology, School of Life Sciences, Sikkim University, Gangtok, India
}

Kinema, an ethnic fermented, non-salted and sticky soybean food is consumed in the eastern part of India. The stickiness is one of the best qualities of good kinema preferred by consumers, which is due to the production of poly- $\gamma$-glutamic acid (PGA). Average load of Bacillus in kinema was $10^{7} \mathrm{cfu} / \mathrm{g}$ and of lactic acid bacteria was $10^{3} \mathrm{cfu} / \mathrm{g}$. Bacillus spp. were screened for PGA-production and isolates of lactic acid

OPEN ACCESS

Edited by:

Andrea Gomez-Zavaglia,

Center for Research

and Development in Food

Cryotechnology, Argentina

Reviewed by:

Harold J. Schreier,

University of Maryland Baltimore

County, USA

Jinshui Zheng,

Huazhong Agricultural University,

China

*Correspondence:

Jyoti P. Tamang

jyoti_tamang@hotmail.com

Specialty section:

This article was submitted to

Food Microbiology,

a section of the journal

Frontiers in Microbiology

Received: 15 April 2016

Accepted: 06 June 2016

Published: 21 June 2016

Citation:

Chettri R, Bhutia MO and

Tamang JP (2016) Poly- $\gamma$-Glutamic

Acid (PGA)-Producing Bacillus Species Isolated from Kinema, Indian

Fermented Soybean Food.

Front. Microbiol. 7:971.

doi: 10.3389/fmicb.2016.00971 bacteria were also tested for degradation of PGA. Only Bacillus produced PGA, none of lactic acid bacteria produced PGA. PGA-producing Bacillus spp. were identified by phenotypic characterization and also by $16 \mathrm{~S}$ rRNA gene sequencing as Bacillus subtilis, $B$. licheniformis and B. sonorensis.

Keywords: Kinema, Bacillus, fermented soybean, poly-glutamic acid

\section{INTRODUCTION}

Poly- $\gamma$-polyglutamic acid (PGA), an amino acid polymer, is not synthesized by ribosomal proteins (Oppermann-Sanio and Steinbüchel, 2002); but is synthesized by Gram-positive bacteria (Yao et al., 2009) and few Gram-negative bacteria (Candela et al., 2009) produced as a polymer outside of the cell (Moraes et al., 2013). PGA-producing bacteria are mainly Bacillus subtilis, $B$. anthracis, $B$. licheniformis, $B$. thuringensis, B. cereus, B. pumilus, B. amyloliquefaciens, B. mojavensis, B. atrophaeus, B. megaterium, Staphylococcus epidermidis, Natrialba aegyptiaca, Lysinibacillus sphaericus, and Fusobacterium nucleatum (Kambourova et al., 2001; Cachat et al., 2008; Meerak et al., 2008; Candela et al., 2009; Cao et al., 2011). PGA is one of the functional properties of microorganisms present in fermented soybean foods (Tamang et al., 2016a). PGA is an anionic, biodegradable, water-soluble, non-toxic, and edible (Yoon et al., 2000; Zhang et al., 2011). Structurally there are two types of PGA: $\gamma$-PGA and $\alpha$-PGA, which are composed of glutamic acids joined by $\gamma$ or $\alpha$ linkages, respectively (Goto and Kunioka, 1992). $\gamma$-PGA has a structure of 5,000-10,000 units of D- and L-glutamic acids that generate a highly viscous solution when it accumulates in the culture medium (Ashiuchi et al., 2001; Tanimoto et al., 2001). PGA produced by Bacillus spp. has potential applications as thickener, cryoprotectant, humectant, drug carrier, biological adhesive, heavy metal absorbent, etc., with biodegradability in the fields of food, cosmetics, medicine, and water treatments (Bajaj and Singhal, 2011; Ogunleye et al., 2015).

Ethnic people of North East India consume spontaneously fermented soybean foods as side dish in meals, which include kinema, tungrymbai, hawaijar, bekang, aakhone, and peruyaan (Tamang, 2015). Kinema is a naturally fermented, sticky, mild-ammoniacal flavor and non-salted soybean food of Sikkim and Darjeeling in India, east Nepal and west Bhutan. It is similar to natto of Japan, 
and chungkokjang of Korea. PGA is produced by Bacillus spp. in many Asian fermented soybean products giving the characteristic of a sticky texture to the product (Urushibata et al., 2002; Nishito et al., 2010) such as natto of Japan (Nagai, 2012; Kada et al., 2013), chungkokjang of Korea (Lee et al., 2010), tungrymbai and bekang of India (Chettri and Tamang, 2014), and thau nao of Thailand (Chunhachart et al., 2006). One of the criteria for good quality of kinema is high stickiness of the product preferred by consumers (Tamang and Nikkuni, 1996). Relative viscosity and stickiness are probably due to production of PGA by Bacillus spp. (Nagai et al., 1994; Tamang and Nikkuni, 1996). B. subtilis KK3:B4, isolated from naturally fermented kinema of India, produced high amount of relative viscosity of 20.1 (Tamang and Nikkuni, 1996). PGAproducing Bacillus strain was isolated from kinema of Nepal (Hara et al., 1995). Though several species of Bacillus such as B. subtilis, B. licheniformis, B. cereus, B. circulans, B. thuringiensis, and $B$. sphaericus were previously isolated from kinema using phenotypic characterization (Sarkar et al., 1994, 2002; Tamang, 2003; Tamang et al., 2016b); however, there has been no further report on PGA-producing strains/species of Bacillus, isolated from kinema samples of India. Hence we conducted this experiment. The present study was to screen PGA-producing species of Bacillus from kinema and to identify species of Bacillus by $16 \mathrm{~S}$ rRNA sequencing.

\section{MATERIALS AND METHODS}

\section{Sample Collection}

Fresh samples of kinema were collected from different markets of Sikkim in India. Samples were collected aseptically in pre-sterile bottles, sealed, labeled, kept in an ice-box and were transported immediately to the laboratory. Samples were stored at $4^{\circ} \mathrm{C}$ for further microbial and biochemical analyses.

\section{Isolation of Microorganisms}

Ten gram of sample was homogenized in $90 \mathrm{~mL}$ sterile physiological saline in a stomacher lab-blender (400, Seward, $\mathrm{UK}$ ) for $1 \mathrm{~min}$ and a serial dilution was made. The diluents were heated at $100^{\circ} \mathrm{C}$ for $2 \mathrm{~min}$ for inactivation of vegetative cells of endospore bacteria (Tamang and Nikkuni, 1996), were isolated and enumerated on nutrient agar (MM012, HiMedia, India), and incubated for $24 \mathrm{~h}$ at $37^{\circ} \mathrm{C}$. Lactic acid bacteria (LAB) were isolated on plates of MRS agar (M641, HiMedia, India) supplemented with $1 \% \mathrm{CaCO}_{3}$ and incubated at $30^{\circ} \mathrm{C}$ in an anaerobic gas-jar (LE002, HiMedia, India) for 48-72 h. Total viable counts were determined on plate count agar (M091A, HiMedia, India) incubated at $30^{\circ} \mathrm{C}$ for $48-72 \mathrm{~h}$. Isolated colonies were purified and were preserved in $15 \%$ (v/v) glycerol at $-20^{\circ} \mathrm{C}$ for further analysis.

\section{Phenotypic Characterization}

Cell morphology and motility of isolates were observed using a phase contrast microscope (Olympus $\mathrm{CH} 3-\mathrm{BH}-\mathrm{PC}$, Japan). Isolates were Gram-stained and tested for production of catalase, carbon dioxide from glucose, ammonia from arginine, growth at different temperatures, in different concentrations of $\mathrm{NaCl}$ and $\mathrm{pH}$ in nutrient broth (M002, HiMedia, India) following the method of Schillinger and Lücke (1987). VogesProskauer test, nitrate reduction, starch hydrolysis, casein hydrolysis, citrate utilization test, bile salt tolerance, anaerobic growth, and sugar fermentations were determined following the method of Duc et al. (2004). Taxonomic key of Slepecky

TABLE 1 | Screening of stickiness, and PGA production at different $\mathrm{pH}$ and temperatures.

\begin{tabular}{|c|c|c|c|c|}
\hline \multirow[t]{2}{*}{ Organisms } & \multirow[t]{2}{*}{ Strain code } & \multirow[t]{2}{*}{ Stickiness (cm) } & \multicolumn{2}{|c|}{ PGA production } \\
\hline & & & pH 7.5 & $30^{\circ} \mathrm{C}$ \\
\hline \multirow{13}{*}{$\begin{array}{l}\text { Bacillus subtilis } \\
(n=13)\end{array}$} & KAS:B5 & 16 & ++ & +++ \\
\hline & KAS:B6 & 18 & ++ & +++ \\
\hline & KAS:B18 & 6 & + & + \\
\hline & KAS:B29 & 16 & ++ & +++ \\
\hline & KAS:B36 & 4 & + & + \\
\hline & KAS:B39 & 15 & ++ & +++ \\
\hline & KLM:B68 & 3 & + & + \\
\hline & KLM:B78 & 3 & + & + \\
\hline & KLM:B86 & 4 & + & + \\
\hline & KLM:B98 & 4 & + & + \\
\hline & KAS:B102 & 20 & ++ & +++ \\
\hline & KLM:B112 & 23 & ++ & +++ \\
\hline & KLM:B114 & 2 & + & + \\
\hline \multirow{4}{*}{$\begin{array}{l}\text { B. licheniformis } \\
(n=4)\end{array}$} & KAS:B46 & 4 & + & + \\
\hline & KAS:B56 & 20 & ++ & +++ \\
\hline & KLM:B92 & 21 & ++ & +++ \\
\hline & KLM:B108 & 2 & + & + \\
\hline \multirow[t]{5}{*}{ B. pumulis $(n=5)$} & KAS:B15 & 3 & + & + \\
\hline & KAS:B48 & 5 & + & + \\
\hline & KLM:B73 & 5 & + & + \\
\hline & KLM:B93 & 6 & + & + \\
\hline & KLM:B106 & 4 & + & + \\
\hline \multirow{8}{*}{$\begin{array}{l}\text { B. sphaericus } \\
(n=8)\end{array}$} & KAS:B9 & 2 & + & + \\
\hline & KAS:B16 & 4 & + & + \\
\hline & KAS:B19 & 5 & + & + \\
\hline & KAS:B49 & 6 & + & + \\
\hline & KLM:B66 & 3 & + & + \\
\hline & KLM:B72 & 2 & + & + \\
\hline & KLM:B82 & 2 & + & + \\
\hline & KLM:B96 & 2 & + & + \\
\hline \multirow[t]{9}{*}{ B. cereus $(n=9)$} & KAS:B8 & 2 & - & - \\
\hline & KAS:B10 & 1 & - & - \\
\hline & KAS:B38 & 2 & - & - \\
\hline & KAS:B58 & 2 & - & - \\
\hline & KLM:B74 & 2 & - & - \\
\hline & KLM:B84 & 2 & - & - \\
\hline & KLM:B85 & 2 & - & - \\
\hline & KLM:B88 & 3 & - & - \\
\hline & KLM:B104 & 1 & - & - \\
\hline
\end{tabular}

$n$, number of isolates in parenthesis. +++ , high clumping of insoluble precipitate; ++ , more clumping of precipitate; +, moderate clumping of precipitate; -, no clumping of precipitate. No precipitate was observed in $\mathrm{pH} 5$ and 9 , and at $45^{\circ} \mathrm{C}$. 


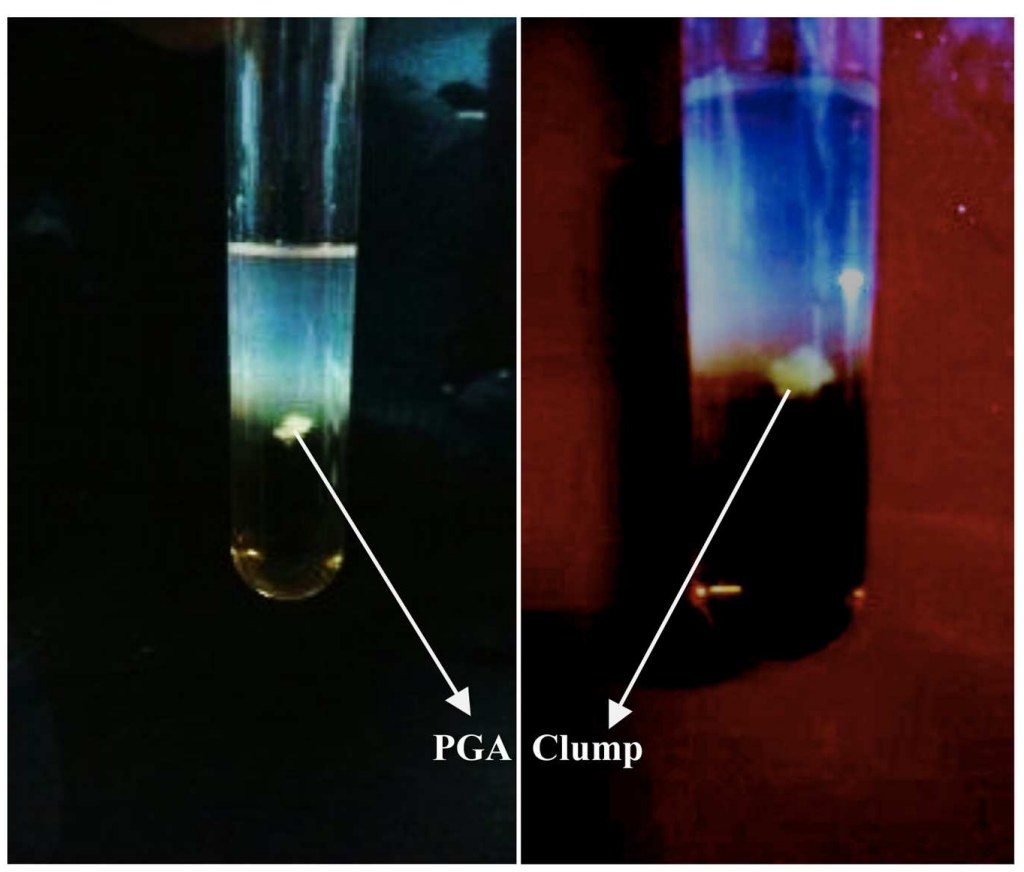

FIGURE 1 | Clumping of insoluble material presumably PGA biopolymer produced by Bacillus subtilis KAS:B5 after addition of ethanol into PGA medium.

and Hemphill (2006) was followed for identification of Bacillus spp.

\section{Measurement of Stickiness}

Cultures were grown on phytone agar (Nagai et al., 1994) at $37^{\circ} \mathrm{C}$ for $24 \mathrm{~h}$ were pulled by touching with an inoculating needle and the stickiness was measured by the length of the thread using scale in $\mathrm{cm}$.

\section{Screening of PGA}

Screening of PGA by bacteria was done with a slightly modification of the method described by Nagai et al. (1997) and Meerak et al. (2007). Bacillus isolates were grown at $37^{\circ} \mathrm{C}$ for $24 \mathrm{~h}$ in a conical flask containing $100 \mathrm{ml}$ of PGA medium that consisted of sodium glutamate $2.0 \%$, glucose $2.0 \%,\left(\mathrm{NH}_{4}\right)_{2} \mathrm{SO}_{4}$ $1.0 \%, \mathrm{Na}_{2} \mathrm{HPO}_{4} \quad 0.1 \%, \mathrm{KH}_{2} \mathrm{PO}_{4} \quad 0.1 \%, \mathrm{MgSO}_{4} \cdot 7 \mathrm{H}_{2} \mathrm{O} \quad 0.05 \%$, $\mathrm{Mn}\left(\mathrm{Cl}_{2}\right)_{4} \cdot \mathrm{H}_{2} \mathrm{O} 0.002 \%, \mathrm{FeCl}_{3} \cdot 7 \mathrm{H}_{2} \mathrm{O} 0.005 \%$ (Kunioka and Goto, 1994). The culture after incubation was centrifuged to obtain a supernatant that contained insoluble material. An equal volume of ethanol was added to the supernatant to get fibrous precipitate presumbly the PGA (Nagai et al., 1997).

Efficiency of PGA of the isolates were tested in different $\mathrm{pH}$ (5, 7.5 , and 9 ) and temperature $\left(30\right.$ and $45^{\circ} \mathrm{C}$ ) following the method of Meerak et al. (2007).

\section{Degradation of PGA}

Screening of LAB for degradation of PGA was performed following the method described by Tanaka et al. (1993). Strains were grown in MRS broth (M369, HiMedia, India), for 18-24 h at $30^{\circ} \mathrm{C}$. The isolates were streaked on MRS agar plates containing
$0.5 \%$ pure PGA (Sigma) solution ( $\mathrm{pH} 4.5$ ), and incubated at $30^{\circ} \mathrm{C}$ for 2-3 days. The plates were flooded with $5 \mathrm{ml}$ of $18 \mathrm{~N}$ $\mathrm{H}_{2} \mathrm{SO}_{4}$ and allowed to stand for $30 \mathrm{~min}$ at room temperature. The presence of halo around the colony determines the degradation of PGA.

\section{Genomic DNA Isolation}

Genomic DNA was isolated according to the method of Wilson (2001). Amplified 16S rDNA was obtained from each strain by polymerase chain reaction (PCR) with the universal primers; forward 5'-AGAGTTTGATCCTGGCTCAG-3' and reverse $5^{\prime}$ AAGGAGGTGATCCAGCCGCA-3' (Weisburg et al., 1991). The amplicons sizes ranged from 914 BP to 1814 BP.

\section{Gel Electrophoresis}

The amplified DNA fragments were separated through gel electrophoresis by applying $10 \mu \mathrm{L}$ of each PCR product with $1.5 \mu \mathrm{L}$ of loading dye [(6×), DV4371, Promega, USA] into the wells of $1.5 \%$ agarose (V3125, Promega) gel containing $1.5 \mu \mathrm{L} / \mathrm{mL}$ ethidium bromide (H5041, Promega). DNA size markers (RMBD135, Genei; G5711, Promega) were added as standard for the calculation of size of the DNA fragments. The gel was run and photographed using gel documentation system (GelDoc FQ, Biorad, USA).

\section{S rDNA Sequence Analysis}

The sequencing reactions were performed using ABI PRISM 3100 Genettic Analyzers (Applied Biosystems) in both direction with universal primers used for amplification. The electrophenogram data for $16 \mathrm{~S}$ rDNA sequence was validated using Chromas 2.33 


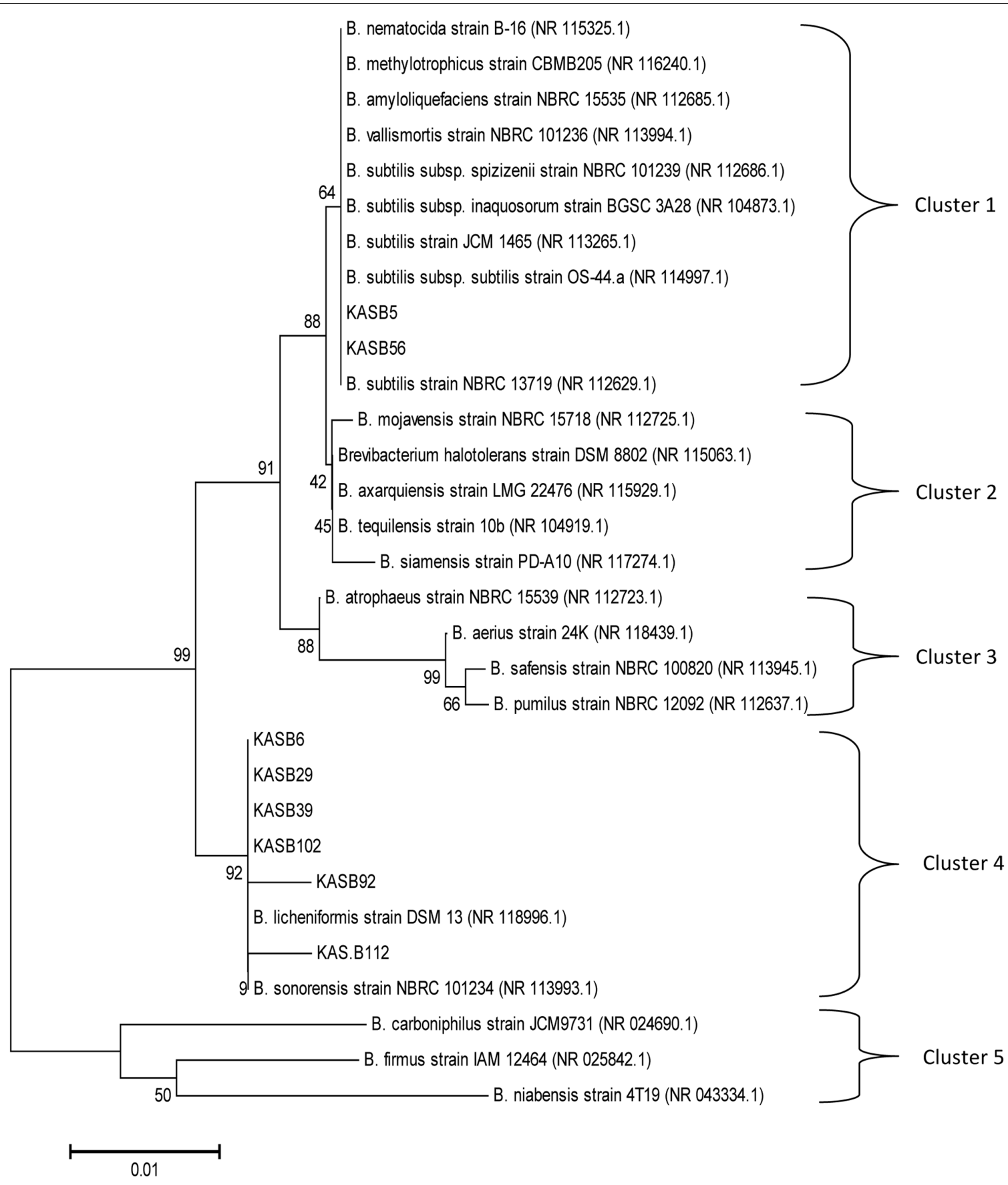

FIGURE 2 | Evolutionary relationships of the analyzed strains with their closest known taxa. The evolutionary history was inferred using the Neighbor-Joining method. The tree was constructed based on the evolutionary distance calculated from 16S rRNA gene sequences using Kimura 2-parameter method. The percentage of replicate trees in which the associated taxa clustered together in the bootstrap test (1,000 replicates) are shown next to the branches. The tree is drawn to scale, with branch lengths in the same units as those of the evolutionary distances.

software. ${ }^{1}$ Sequences obtained were matched with previously published bacterial 16S rDNA sequences available in the GenBank database using BLAST and the Ribosomal Database Project (RDP).

${ }^{1}$ www.technelysium.com.au

\section{Phylogenetic Analysis}

For phylogenetic analysis, 16S rDNA sequence of the isolates and reference sequence retrieved from NCBI-GenBank database were aligned with Clustal Omega. The resulting alignment were analysed with MEGA 6.0 to construct the phylogenetic tree. Phylogenetic tree was inferred with 
TABLE 2 | Homogeny of PGA-producing Bacillus isolated from kinema.

\begin{tabular}{llcc}
\hline Strain code & Bacillus & $\begin{array}{c}\text { Accession } \\
\text { number }\end{array}$ & $\begin{array}{c}\text { Homogeny } \\
\text { (\% similarity) }\end{array}$ \\
\hline KAS:B5 & Bacillus subtilis & KX262911 & 96 \\
KAS:B6 & B. licheniformis & KX262910 & 98 \\
KAS:B29 & B. licheniformis & KX261423 & 94 \\
KAS:B39 & B. licheniformis & KX261424 & 97 \\
KAS:B56 & B. subtilis & KX262912 & 97 \\
KAS:B92 & B. licheniformis & KX261426 & 97 \\
KAS:B102 & B. licheniformis & KX261425 & 96 \\
KAS:B112 & B. sonorensis & KX262913 & 97 \\
\hline
\end{tabular}

neighbor-joining (NJ) method (Saitou and Nei, 1987). Sequence divergence among the strain were quantified using Kimura2-paramater distance model (Kimura, 1980). A total of 1,000 bootstrap replication were calculated for evaluation of the tree topology.

\section{RESULTS AND DISCUSSION}

\section{Phenotypic Identification}

The average population of Bacillus spp. in kinema was $10^{7}$ $\mathrm{cfu} / \mathrm{g}, \mathrm{LAB}$ was $10^{3} \mathrm{cfu} / \mathrm{g}$ and total viable counts were $10 \mathrm{cfu} / \mathrm{g}$, respectively (data not shown). Thirty-nine isolates of Bacillus were isolated from 10 samples of kinema. Based on phenotypic characterization (data not shown) five species of Bacillus were identified from 10 samples of kinema as B. subtilis, $B$. licheniformis, B. pumulis, B. sphaericus and B. cereus (Table 1). About $90 \%$ of the total bacterial population found in kinema was Bacillus, indicating that Bacillus is the dominant bacterium in kinema. Sarkar and Tamang (1994) also reported that Bacillus is the predominant bacterium in kinema. B. subtilis, B. licheniformis, B. cereus, B. circulans, B. thuringiensis, and B. sphaericus were reported from kinema sample earlier (Sarkar et al., 1994, 2002; Nout et al., 1998; Tamang, 2003).

\section{Screening of PGA Production}

Stickiness of 39 isolates of Bacillus was measured (Table 1). The ability of 39 isolates of Bacillus were tested for production of PGA in PGA medium (Kunioka and Goto, 1994) in $\mathrm{pH} 5,7.5$, and 9, and at $30 \mathrm{C}$ and $45^{\circ} \mathrm{C}$ (Table 1). The isolates formed an insoluble material or fibrous precipitate after addition of equal volume of ethanol into the PGA medium (Figure 1) presumbly PGA biopolymer (Nagai et al., 1997; Ashiuchi et al., 2001). All species of Bacillus showed fibrous precipitate indicating the absence of PGA production except $B$. cereus.

We tested 25 isolates of $\mathrm{LAB}$ isolated from kinema for their ability to degrade poly-glutamic acid (PGA) to know whether LAB also produce PGA in kinema (data not shown). All LAB isolates were found to degrade PGA, indicating that they have no role in PGA production. Similar observations of degradation of PGA by LAB in fermented soybean were made earlier (Kimura and Fujimoto, 2010; Chettri and Tamang, 2014).

\section{Molecular Characterization}

On the basis of high $(+++)$ fibrous precipitate at $30^{\circ} \mathrm{C}$ and $\mathrm{pH} 7.5$, and stickiness of $>15 \mathrm{~cm}$ (Table 1), 8 strains of Bacillus viz. KAS:B5, KAS:B29, KAS:B39, KAS:B56, KAS:B102, KAS:B6, KAS:B92, and KAS:B112 were selected and were identified by $16 \mathrm{~S}$ rRNA sequencing. Based on the similarity search with blastN and EzTaxon server the strain KAS:B5 was identified as B. subtilis, KAS:B6 as B. licheniformis, KAS:B29 as B. licheniformis, KAS:B39 as B. licheniformis, KAS:B56 as B. subtilis, KAS:B92 as B. licheniformis, KAS:B102 as B. licheniformis and KAS:B112 as $B$. sonorensis. Recovery of $B$. sonorensis from kinema is the first report.

Phylogenetic tree was constructed with neighbor joining method based on the evolutionary distance calculated from 1,000 replicates has showed 5 distinct clusters (Figure 2), which were separated on a scale of 0.01 nucleotide substitution. The homogeny similarity of Bacillus spp. and accession numbers were shown in Table 2. Out of 8 PGA-producing strains KAS:B5 and KAS:B56 showed similarities with B. substilis strain NBRC13719, B. subtilis subsp. subtilis strain OS44a and other strains of subtilis like JCM1465, NBRC 101236, NBRC 101239, and BGSC 3A28 with $64 \%$ of similarity percentage in cluster 1 . KAS:B6, KAS:B29, KAS:B39, KAS:B102, and KAS:B92 were found in same clade of cluster 4 showing similarities with B. licheniformis DSM12 with 92\% similarity and KAS:B112 showed similarities with B. sonorensis strain NBRC 101234 with $90 \%$ similarity. Strains KAS:B92 and KAS:B112 were found to show a distance gap between the other species of cluster 4 indicating the difference in nucleotide sequence and evolutionary lineage. In this paper, we could find that $B$. subtilis and B. licheniformis are PGAproducing bacteria in kinema. B. subtilis and B. licheniformis are the most widely used industrial producers of $\gamma$-PGA (Kambourova et al., 2001; Stanley and Lazazzera, 2005; Zhang et al., 2011).

\section{CONCLUSION}

Consumers prefer slimy texture of kinema as good quality product. Presumably slimy material in fermented soybean food is polyglutamic acid, which has been reported from several Asian fermented foods produced by Bacillus spp. PGA, has several applications as foods as well as non-foods. The present study revealed that some species of Bacillus produced PGA in kinema. Further investigation is needed to characterize and purify PGA produced by Bacillus spp. during natural fermentation of kinema.

\section{AUTHOR CONTRIBUTIONS}

RC: screening of PGA-producing Bacillus from kinema, molecular identification of Bacillus, screening go PGA, stickiness, and preparation of draft paper. MOB: phenotypic identification. JPT: analysis of data, compilation and finalization of paper. 


\section{REFERENCES}

Ashiuchi, M., Kamei, T., Baek, D. H., Shin, S. Y., Sung, M. H., Soda, K., et al. (2001). Isolation of Bacillus subtilis (chungkookjang), a poly- $\gamma$-glutamate producer with high genetic competence. Appl. Microbiol. Biotechnol. 57, 764-769. doi: 10.1007/s00253-001-0848-9

Bajaj, I., and Singhal, R. (2011). Poly (glutamic acid) an emerging biopolymer of commercial interest. Bioresour. Technol. 102, 5551-5561. doi: 10.1016/j.biortech.2011.02.047

Cachat, E., Barker, M., Read, T. D., and Priest, F. G. (2008). A Bacillus thuringiensis strain producing a polyglutamate capsule resembling that of Bacillus anthracis. FEMS Microbiol. Lett. 285, 220-226. doi: 10.1111/j.1574-6968.2008.01231.x

Candela, T., Moya, M., Haustant, M., and Fouet, A. (2009). Fusobacterium nucleatum, the first Gram-negative bacterium demonstrated to produce polyglutamate. Can. J. Microbiol. 55, 627-632. doi: 10.1139/w09-003

Cao, M., Geng, W., Liu, L., Song, C., Xie, H., Guo, W., et al. (2011). Glutamic acid independent production of poly- $\gamma$-glutamic acid by Bacillus amyloliquefaciens LL3 and cloning of pgsBCA genes. Bioresour. Technol. 102, 4251-4257. doi: 10.1016/j.biortech.2010.12.065

Chettri, R., and Tamang, J. P. (2014). Functional properties of Tungrymbai and Bekang, naturally fermented soybean foods of North East India. Int. J. Ferment. Foods 3, 87-103. doi: 10.5958/2321-712X.2014.01311.8

Chunhachart, O., Itoh, T., Sukchotiratana, M., Tanimoto, H., and Tahara, Y. (2006). Characterization of (C)-glutamyl hydrolase produced by Bacillus sp. isolated from Thai thua-nao. Biosci. Biotechnol. Biochem. 70, 2779-2782. doi: $10.1271 / \mathrm{bbb} .60280$

Duc, L. H., Hong, H. A., Barbosa, T. M., Henriques, A. O., and Cutting, S. M. (2004). Characterization of Bacillus probiotics available for human use. Appl. Environ. Microbiol. 70, 2161-2171. doi: 10.1128/AEM.70.4.2161-2171.2004

Goto, A., and Kunioka, M. (1992). Biosynthesis and hydrolysis of poly $(\gamma$-glutamic acid) from Bacillus subtilis IFO3335. Biosci. Biotechnol. Biochem. 56, 1031-1035. doi: $10.1271 /$ bbb.56.1031

Hara, T., Saito, H., Iwamoto, N., and Kaneko, S. (1995). Plasmid analysis in Polyglutamate producing Bacillus strain isolated from non-salty fermented soybean food, "Kinema" in Nepal. J. Gen. Appl. Microbiol. 41, 3-9. doi: 10.2323/jgam.41.3

Kada, S., Ishikawa, A., Ohshima, Y., and Yoshida, K. (2013). Alkaline serine protease AprE plays an essential role in poly- $\gamma$-glutamate production during natto fermentation. Biosci. Biotechnol. Biochem. 77, 802-809. doi: $10.1271 /$ bbb. 120965

Kambourova, M., Tangney, M., and Priest, F. G. (2001). Regulation of polyglutamic acid synthesis by glutamate in Bacillus licheniformis and Bacillus subtilis. Appl. Environ. Microbiol. 67, 1004-1007. doi: 10.1128/AEM.67.2.1004-1007.2001

Kimura, K., and Fujimoto, Z. (2010). "Enzymatic degradation of poly-gammaglutamic acid," in Amino-Acid Homopolymers Occurring in Nature, 95 Microbiology Monographs 15, ed. Y. Hamano, (Berlin: Springer-Verlag), 25-116.

Kimura, M. (1980). A simple method for estimating evolutionary rate of base substitutions through comparative studies of nucleotide sequences. J. Mol. Evol. 16, 111-120. doi: 10.1007/BF01731581

Kunioka, M., and Goto, A. (1994). Biosynthesis of poly ( $\gamma$-glutamic acid) from L-glutamic acid, citric acid, and ammonium sulfate in Bacillus subtilis IFO3335. Appl. Microbiol. Biotechnol. 40, 867-872. doi: 10.1007/BF00173990

Lee, H., Chang, M. J., and Kim, S. H. (2010). Effects of poly-gamma-glutamic acid on serum and brain concentrations of glutamate and GABA in diet-induced obese rats. Nutr. Res. Pract. 4, 23-29. doi: 10.4162/nrp.2010.4.1.23

Meerak, J., Lida, H., Watanabe, Y., Miyashita, M., Sato, H., Nakagawa, Y., et al. (2007). Phylogeny of poly- $\gamma$-glutamic acid-producing Bacillus strains isolated from fermented soybean foods manufactured in Asian countries. J. Gen. Appl. Microbiol. 53, 315-323. doi: 10.2323/jgam.53.315

Meerak, J., Yukphan, P., Miyashita, M., Sato, H., Nakagawa, Y., and Tahara, Y. (2008). Phylogeny of (-polyglutamic acid-producing Bacillus strains isolated from a fermented locust bean product manufactured in West Africa. J. Gen. Appl. Microbiol. 54, 159-166. doi: 10.2323/jgam.54.159

Moraes, L. P., Brito, P. N., and Alegre, R. M. (2013). The existing studies on biosynthesis of poly $(\gamma$-glutamic acid) by fermentation. Food Public Health 3, 28-36.

Nagai, T. (2012). Overview of studies on Bacillus subtilis (natto) bacteriophages and the prospects. JARQ 46, 305-310. doi: 10.6090/jarq.46.305
Nagai, T., Koguchi, K., and Itoh, Y. (1997). Chemical analysis of poly-(-glutamic acid produced by plasmid-free Bacillus subtilis (natto): evidence that plasmids are not involved in poly-glutamic acid production. J. Gen. Appl. Microbiol. 43, 139-143. doi: 10.2323/jgam.43.139

Nagai, T., Nishimura, K., Suzuki, H., Banba, Y., Sasaki, H., and Kiuchi, K. (1994). Isolation and characterization of Bacillus subtilis strain producing natto with strong umami-taste and high viscosity. Nippon Shokuhin Kogyo Gakkaishi 41, 123-128. doi: 10.3136/nskkk1962.41.123

Nishito, Y., Osana, Y., Hachiya, T., Popendorf, K., Toyoda, A., Fujiyama, A., et al. (2010). Whole genome assembly of a natto production strain Bacillus subtilis natto from very short read data. BMC Genomics 11:243. doi: 10.1186/14712164-11243

Nout, M. J. R., Bakshi, D., and Sarkar, P. K. (1998). Microbiological safety of Kinema, a fermented soyabean food. Food Control 9, 357-362. doi: 10.1016/S0956-7135(98)00126-1

Ogunleye, A., Bhat, A., Irorere, V. U., Hill, D., Williams, C., and Radecka, I. (2015). Poly- $\gamma$-glutamic acid: production, properties and applications. Microbiology 161, 1-17. doi: 10.1099/mic.0.081448-0

Oppermann-Sanio, F. B., and Steinbüchel, A. (2002). Occurrence, functions and biosynthesis of polyamides in microorganisms and biotechnological production. Naturwissenschaften 89, 11-22. doi: 10.1007/s00114-0010280-0

Saitou, N., and Nei, M. (1987). The Neighbor-joining method: a new method for reconstructing phylogenetic trees. Mol. Biol. Evol. 4, 406-425.

Sarkar, P. K., Hasenack, B., and Nout, M. J. R. (2002). Diversity and functionality of Bacillus and related genera isolated from spontaneously fermented soybeans (Indian Kinema) and locust beans (African Soumbala). Int. J. Food Microbiol. 77, 175-186. doi: 10.1016/S0168-1605(02)00124-1

Sarkar, P. K., and Tamang, J. P. (1994). The influence of process variables and inoculum composition on the sensory quality of kinema. Food Microbiol. 11, 317-325. doi: 10.1006/fmic.1994.1036

Sarkar, P. K., Tamang, J. P., Cook, P. E., and Owens, J. D. (1994). Kinema-a traditional soybean fermented food: proximate composition and microflora. Food Microbiol. 11, 47-55. doi: 10.1006/fmic.1994.1007

Schillinger, U., and Lücke, F. K. (1987). Identification of lactobacilli from meat and meat products. Food Microbiol. 4, 199-208. doi: 10.1016/0740-0020(87) 90002-5

Slepecky, R. A., and Hemphill, H. E. (2006). “The genus Bacillus-nonmedical," in The Prokaryotes, A Handbook on the Biology of Bacteria: Bacteria, Firmicutes, Cyanobacteria, 3rd Edn, Vol. 4, eds M. Dworkin, S. Falkow, E. Rosenberg, K.-H. Schleifer, and E. Stackebrandt (New York, NY: Springer-Verlag), 530-562.

Stanley, N. R., and Lazazzera, B. A. (2005). Defining the genetic differences between wild and domestic strains of Bacillus subtilis that affect poly- $\gamma$-dl-glutamic acid production and biofilm formation. Mol. Microbiol. 57, 1143-1158. doi: 10.1111/j.1365-2958.2005.04746.x

Tamang, J. P. (2003). Native microorganisms in fermentation of kinema. Indian J. Microbiol. 43, 127-130.

Tamang, J. P. (2015). Naturally fermented ethnic soybean foods of India. J. Ethnic Foods 2, 8-17. doi: 10.1016/j.jef.2015.02.003

Tamang, J. P., and Nikkuni, S. (1996). Selection of starter culture for production of kinema, fermented soybean food of the Himalaya. World J. Microbiol. Biotechnol. 12, 629-635. doi: 10.1007/BF00327727

Tamang, J. P., Shin, D. H., Jung, S. J., and Chae, S. W. (2016a). Functional properties of microorganisms in fermented foods. Front. Microbiol. 7:578. doi: $10.3389 /$ fmicb. 2016.00578

Tamang, J. P., Watanabe, K., and Holzapfel, W. H. (2016b). Review: diversity of microorganisms in global fermented foods and beverages. Front. Microbiol. 7:377. doi: 10.3389/fmicb.2016.00377

Tanaka, T., Yaguchi, T., Hiruta, O., Futamura, T., Uotani, K., Satoh, A., et al. (1993). Screening for microorganisms having poly ((-glutamic acid) endohydrolase activity and the enzyme production by Myrothecium sp.TM-4222. Biosci. Biotechnol. Biochem. 57, 1809-1810. doi: 10.1271/bbb. 57.1809

Tanimoto, H., Mori, M., Motoki, M., Torii, K., Kadowaki, M., and Noguchi, T. (2001). Natto mucilage containing poly- $\gamma$-glutamic acid increases soluble calcium in the rat small intestine. Biosci. Biotechnol. Biochem. 65, 516-521. doi: $10.1271 /$ bbb. 65.516 
Urushibata, Y., Tokuyama, S., and Tahara, Y. (2002). Characterization of the Bacillus subtilis ywsC gene, involved in gamma-polyglutamic acid production. J. Bacteriol. 184, 337-343. doi: 10.1128/JB.184.2. 337-343

Weisburg, W. G., Barns, S. M., Pelletier, D. A., and Lane, D. J. (1991). 16S ribosomal DNA amplification for phylogenetic study. J. Bacteriol. 173, 697-703.

Wilson, K. (2001). Preparation of genomic DNA from bacteria. Curr. Protoc. Mol. Biol. Chap. 2, Unit 2.4. doi: 10.1002/0471142727.mb02 $04 \mathrm{~s} 56$

Yao, J., Jing, J., Xu, H., Liang, J., Wu, Q., Feng, X., et al. (2009). Investigation on enzymatic degradation of $\gamma$-polyglutamic acid from Bacillus subtilis NX-2. J. Mol. Catal. B 56, 158-164. doi: 10.1016/j.molcatb.2007. 12.027

Yoon, S., Do, J., Lee, S., and Chag, H. (2000). Production of poly- $\delta$-glutamic acid by fed-batch culture of Bacillus licheniformis. Biotechnol. Lett. 22, 585-588. doi: 10.1023/A:1005610400511
Zhang, D., Xu, Z., Xu, H., Feng, X., Li, S., Cai, H., et al. (2011). Improvement of poly( $\gamma$-glutamic acid) biosynthesis and quantitative metabolic flux analysis of a two-stage strategy for agitation speed control in the culture of Bacillus subtilis NX-2. Biotechnol. Bioprocess. Eng. 16, 1144-1151. doi: 10.1007/s12257011-0074-y

Conflict of Interest Statement: The authors declare that the research was conducted in the absence of any commercial or financial relationships that could be construed as a potential conflict of interest.

Copyright (C) 2016 Chettri, Bhutia and Tamang. This is an open-access article distributed under the terms of the Creative Commons Attribution License (CC BY). The use, distribution or reproduction in other forums is permitted, provided the original author(s) or licensor are credited and that the original publication in this journal is cited, in accordance with accepted academic practice. No use, distribution or reproduction is permitted which does not comply with these terms. 